\title{
M orbidade por acidentes de transporte entre jovens de Goiânia, Goiás
}

\author{
Traffic injuries among youth in Goiânia, Goiás State
}

\author{
Carlos Roberto Caixeta $^{1}$ \\ Ruth M inamisava ${ }^{2}$ \\ Lizete $M$ alagoni de Almeida Caval cante O liveira ${ }^{2}$ \\ Virginia Visconde Brasil ${ }^{2}$
}

Abstract Traffic injuries are currently one of the world's main public health issues in both developed and developing countries. This study aimed to describe the circumstancesinvolved in the traffic accidents and the profile of the victims attended at the Emergency $\mathrm{H}$ ospital of Goiânia, aged 15 to 24 years and residents in Goiânia, Goiás State, Brazil. It's a prospective cross- sectional study carried out from August 2005 to August 2006 by systematic sampling. Data wereanalyzed by descriptive statistics. M ost of the 301 victims were male, mean age of $19.94 \pm 2.73$ years, and drivers. $\mathrm{M}$ otorcycles $(67.33 \%)$ and bicycles (16.67\%) were frequently mode of transport. A ccidents usually occurred around 6pm, on Fridays and Sundays. The victims were generally traveling/walking to/ from exercise, sports, school, recreational or entertainment activities. Suspicion of alcohol use was reported by $15.16 \%$ of the cases. M ore motorcyclists believed that there was imprudence/ negligence than the cyclists. Security equipment was not used by $8.58 \%$ of motorcyclists, $95.45 \%$ of cyclists. Educational measures for motorcyclists and law enforcement highlighting the nights and weekends are needed.

Key words Morbidity, Injury, Traffic accidents, Transportation
Resumo Acidentes detransporteconstituem problema mundial desaúde pública, especialmentenos países em desenvolvimento. 0 objetivo foi descrever o perfil das vítimas e circunstâncias dos acidentes de transportes com residentes de Goiânia (GO), na faixa etária de 15 a 24 anos e atendidos no H ospital deU rgências. Estudo transversal prospectivo, realizado de agosto de 2005 a agosto de 2006, por amostragem sistemática de 301 vítimas de acidentes de transporte. Os dados primários foram tratados por meio de estatística descritiva. A maioria era do sexo masculino, com idade média de 19,88 $\pm 2,7$ anos e condutor dos veículos. 0 meio de transporte mais utilizado foi motocicleta $(67,33 \%)$, seguido da bicicleta (16,67\%). Os acidentes ocorreram predominantemente em torno das 18 horas, sextas-feiras e domingos. As vítimas estavam principalmente no trajeto para atividades físicas, esportivas, escolares, lazer e entretenimento. A suspeita do uso deálcool foi relatada por $15,16 \%$ dos entrevistados. Comparados aos ciclistas, mais motociclistas julgaram que houve imprudência/negligência no acidente. Equipamentos de segurança não foram usados por $8,58 \%$ dos motociclistas e 95,45\% dos ciclistas. São necessárias medidas de educação dirigida aos motocicl istas e fiscalização que priorizem o período noturno e os finais de semana.

Palavras-chave M orbidade, Acidentes de transporte, Causas externas
Goiás. 1 Avenidas/n, Leste

Goiânia GO

caixeta2@uol.com.br

2 Faculdade de Enfermagem, UniversidadeFederal de

Goiás. 
Introdução

Estima-se em 1,2 milhões o número de mortes em 50 milhões de acidentes de trânsito no mundo, com projeções de aumento de mortes relacionadas ao crescimento econômico de países menos desenvolvidos ${ }^{1-3}$. Esses acidentes têm se configurado como problema de saúde pública pela alta mortalidade, morbidade, custos, anos potenciais de vida perdidos eimpacto para o indivíduo, sua família e sociedade ${ }^{4,5}$

Uma análiseincluindo dozepaíses das Américas concluiu que os acidentes com veícul os a motor foram responsáveis por $20-30 \%$ dos óbitos por causas externas no Brasil, Belize, Canadá, M éxico, Porto Rico e nos Estados Unidos, entre 1985 e 2001. Esse estudo ainda mostrou que as maiores taxas de mortalidade por acidentes com veículos a motor foram encontradas no Brasil ${ }^{6}$.

No Brasil, o número de óbitos por acidente detransporteentre 1994 e2004 aumentou 20,8\% para a população total e $24,3 \%$ entre os jovens ${ }^{7}$. 0 aumento de mortes a cada ano decorre de investimentos em transportes rodoviários em de trimento de outros meios de transportes, do aumento da frota de veículos nos centros urbanos e da escassez de ações reguladoras e educacionais 8 . 0 transporte público inseguro, a alta velocidade e a diversidade dos tipos de veículos também podem contribuir para esse aumento ${ }^{1}$.

A redução dos acidentes constitui um dos maiores desafios para a saúde pública, sendo necessário o desenvolvimento de estudos para compreensão da verdadeira magnitude do problema e distribuição das causas para sua prevenção e promoção da segurança ${ }^{4}$. Uma análise histórica do número de acidentes com vítimas por 10.000 veículos entre 1996 e 2005 mostrou aumento de 89 para 91,1 no Brasil e de 83,2 para 209,8 no Estado de Goiás9.

Embora os acidentes de transporte no Brasil afetem indivíduos de todas as idades, em 2007, 0 número de internações de jovens foi superior ao de outras fai xas etárias ${ }^{10}$. Goiânia (GO) e Vitória (ES) lideraram, em 2004, a lista de capitais com as maiores taxas de óbitos juvenis por acidentes de transporte ${ }^{7}$. Cada morte ocorrida nas faixas etárias de 15-19 e 20-24 anos (considerando o limitede 65 anos) corresponde, respectivamente, a uma perda de 47,5 e 42,5 anos potenciais de vida perdidos ${ }^{11}$. Isso representa grande prejuízo para sociedade, ao ser privada do potencial intelectual e econômico das vítimas que estão entrando no mercado de trabalho.

Dados estatísticos sobre mortalidade são essenciais para definir prioridades e alocação de re cursos para a saúde e muitas vezes são "o único instrumento para medir o nível de saúde da comunidade e avaliar programas de saúde"11. Todavia, estudos de morbidade com dados primários, raros nos países em desenvolvimento, também são necessários para conhecer o padrão e as circunstâncias dos acidentes, avaliar tendências e o impacto das intervenções de prevenção propostas, adequar os serviços de emergência e reabilitação e, assim, viabilizar estratégias adequadas $5^{4,12,13}$.

0 objetivo desse estudo foi descrever o perfil das vítimas e as circunstâncias dos acidentes de transporte com vítimas de 15 a 24 anos de idade, residentes no município de Goiânia ( $G 0$ ) e atendidas no Hospital de Urgências de Goiânia (HUGO).

\section{M etodologia}

Este é um estudo transversal descritivo, com dados primários coletados prospectivamente no principal serviço de emergência de Goiânia, capital do Estado de Goiás, Região Centro-O este do Brasil. A população estimada de Goiânia para 1으 dejulho de2005 é de 1.201.007 habitantes, sendo 264.005 (21,98\%) de jovens de 15 a 24 anos de

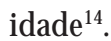

O local selecionado para a coleta de dadoséo único serviço de emergência de referência para traumas em Goiânia. Osserviços públicos deatendimento móvel pré-hospitalar têm como rotina encaminhar todos os casos de trauma para o hospital citado. Além disso, esse serviço é amplamente conhecido pela população goianiense e utilizado por todas as camadas sociais. Em levantamento prévio nas fichas de pronto atendimento, estimou-se o número médio de atendimentos em 900 casos por dia, sendo que os acidentes de transporte foram responsáveis por $30 \%$ dos jovens atendidos por causas externas, residentes ou não em Goiânia.

Para o presente estudo, foram realizadas entrevistas face to face com as vítimas ou seus familiares no Serviço deEmergência do H UGO ou no domicílio, quando não havia condições de proceder à coleta de dados no serviço de saúde. Foram incluídos todos os casos de jovens com idade de 15 a 24 anos, residentes no município de Goiânia, vítimas de acidente de transporte. Foram excluídos os casos de retorno por acidente detransporte. A coleta de dadosfoi realizada por enfermeiros eestudantes de enfermagem emedicinatreinados, de 5 de agosto de 2005 a 4 deagosto de 2006, usando formulário de entrevista estruturado. Reuniões mensais até o final da coleta de 
dados foram conduzidas para revisar os formulários preenchidos e para resolver problemas ocorridos no período.

0 instrumento de coleta de dados pré-testado continha variáveis sociodemográficas (idade, sexo, religião, escolaridade, ocupação, com quem mora, renda) e sobre as circunstâncias do acidente (dia ehora do acidente, meio de transporte, equipamentos de segurança, ati vidade exercida no momento do acidente, uso de álcool/drogas, papel da vítima e se considera que houve imprudência/negligência no momento do acidente). Quando possível, a confiabilidade dos dados foi checada com observação direta e em prontuários. Para complementar os dados que os respondentes desconheciam, foi realizado contato telefônico ou visita à residência do acidentado.

Calculou-se uma amostra de 295 casos, considerando uma prevalência de pelo menos $20 \%$ de jovens residentes em Goiânia atendidos por acidente de transporte, precisão de $5 \%$, efeito de desenho de 1,2 e erro alfa de $5 \%$. A amostragem sistemática foi definida considerando os dias da semana e os horários do dia (quatro turnos de seis horas).

Os dados foram digitados em dupla entrada usando o programa Epilnfo ${ }^{T M}$ for Windows ${ }^{15}$ para checagem de inconsistências. 0 tempo entre a hora do acidente e a hora do atendimento foi registrado em número de horas completas. $\mathrm{Na}$ análise dos dados, calcularam-se prevalências e diferenças de proporções com intervalo de $95 \%$ de confiança.

Este estudo foi aprovado pelo Comitê deÉtica em Pesquisa do Hospital deU rgências de Goiâ- nia e todos os sujeitos assinaram o termo deconsentimento livreeesclarecido.

\section{Resultados}

Foram entrevistadas 301 vítimas de acidentes de transporte e, destas, 295 (98\%) foram indivíduos que sofreram acidentes de trânsito. A mediana do tempo decorrido entre o acidente eo atendimento no HUGO foi uma hora, sendo os percentis 5, 10, 25, 50, 75, 90 e 95: 0, 0, 1, 1, 2, 4 e 5 horas, respectivamente. 0 s meios de transporte mais utilizados pelas vítimas foram motocicletas e bicicletas (Gráfico 1).

A idade média foi de 19,94 $\pm 2,73$ anos e as vítimas com idade menor de dezoito anos representaram $24 \%$ do total. A maioria dos acidentados era motociclista, sendo que $14,19 \%$ (22/155) dos condutores de motocicleta tinham idade inferior a dezoito anos. Dentre os motociclistas e ciclistas, 8,58\% e 95,45\%, respectivamente, não estavam usando capacete. Dos 22 ocupantes de automóveis, 50,00\% não usavam cinto de segurança e eram passageiros.

A maioria $(72,42 \%)$ da população estudada era do sexo masculino, com uma razão de sexos de 2,62 homens para cada mulher (7,33:1 para ciclistas e 2,88:1 para motociclistas). A prática religiosa foi referida por $56,94 \%$ das vítimas e 81,48\% moravam com pelo menos um dos pais e/ou companheiro(a) (Tabela 1). Jovens com escolaridadeaté o primeiro grau incompleto perfizeram $25,08 \%$ dos casos. A renda familiar variou entre $R \$ 300,00$ e $R \$ 8.000,00$ (percentil $250=R \$$

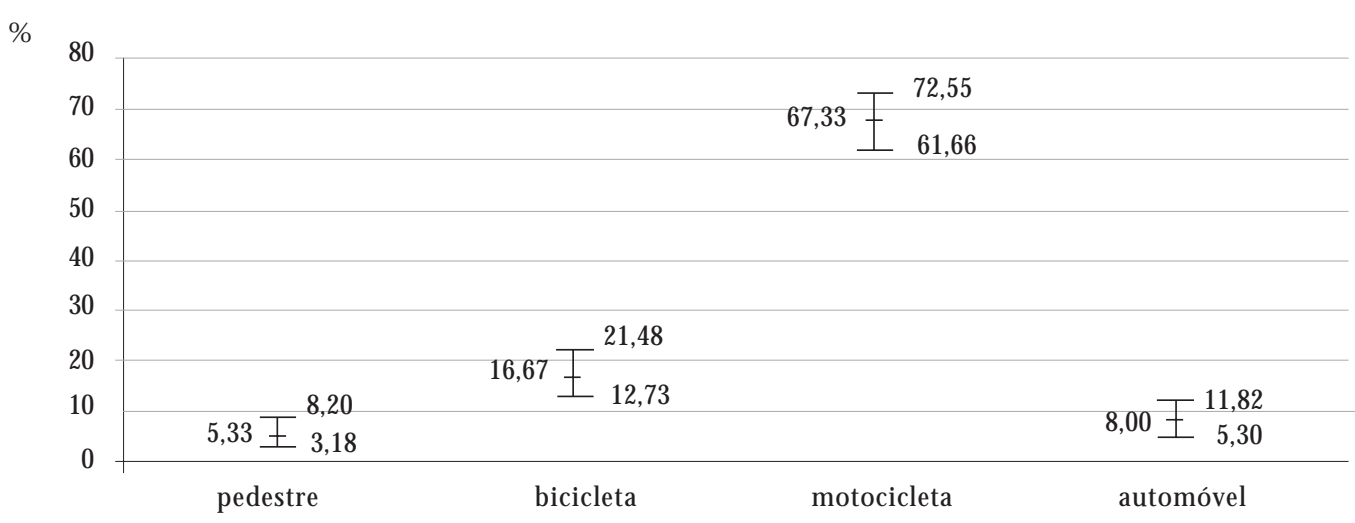

Gráfico 1. Prevalências e intervalos de confiança do meio de transporte usado por 301 vítimas de acidentes de transporte com idade entre 15 e 24 anos, residentes no município de Goiânia (GO) e atendidas no HUGO. Goiânia (GO), agosto de 2005 a agosto de 2006. 
600,00 , percentil $50^{\circ}=R \$ 975,00$ epercentil $75^{\circ}=$ $R \$ 1.500,00)$. Os dados sobre a ocupação das vítimas dos acidentes de transporte indicam que $48,76 \%$ apenas trabalhavam e $27,71 \%$ trabal havam e estudavam, resultando em $75,78 \%$. Eram exclusivamente estudantes $19,64 \%$ das vítimas.

$\mathrm{N}$ as sextas-feiras e nos domingos aconteceram, proporcionalmente, mais acidentes que às segundas, terças, quartas e quintas-feiras $(p<0,05)$. 0 motociclista foi o quemais seacidentou em todos os dias da semana, seguido do ciclista. Os ocupantes de automóveis se acidentaram mais aos sábados e domingos (Gráfico 2). A maioria dos acidentes ocorreu entre 7-8h, 12-14h e 17-20h (Gráfico 3), mas o horário em que mais ocorreram acidentes com motociclistas foi em torno das $18 \mathrm{~h}$ e das $14 \mathrm{~h}$.

Tabela 1. Caracterização socioodemográfica de 301 vítimas de acidentes de transporte de 15 a 24 anos, residentes no município de Goiânia (GO) e atendidas no HUGO, segundo o meio de transporte. Goiânia (GO), 2006.

\begin{tabular}{|c|c|c|c|c|c|c|}
\hline \multirow[b]{2}{*}{$\begin{array}{c}\text { Características } \\
\text { sociodemográficas }\end{array}$} & \multicolumn{5}{|c|}{ M eio de transporte } & \multirow[b]{2}{*}{$\begin{array}{l}\text { Total } \\
\mathrm{N}=301\end{array}$} \\
\hline & $\begin{array}{l}\text { Pedestre } \\
\mathrm{N}=16\end{array}$ & $\begin{array}{l}\text { Ciclista } \\
\mathrm{N}=50\end{array}$ & $\begin{array}{l}\text { Motociclista } \\
\qquad \mathrm{N}=203\end{array}$ & $\begin{array}{c}\text { Ocupante de } \\
\text { automóvel } \\
N=24\end{array}$ & $\begin{array}{c}\text { Outros } \\
N=8\end{array}$ & \\
\hline \multicolumn{7}{|l|}{ Sexo } \\
\hline Masculino & 8 & 44 & 150 & 10 & 6 & 218 \\
\hline Feminino & 8 & 6 & 52 & 14 & 2 & 82 \\
\hline Ignorado & 0 & 0 & 1 & 0 & 0 & 1 \\
\hline \multicolumn{7}{|l|}{ Faixa etária } \\
\hline$<18$ anos & 8 & 23 & 36 & 4 & 1 & 72 \\
\hline$\geq 18$ anos & 8 & 27 & 166 & 20 & 7 & 228 \\
\hline Ignorado & 0 & 0 & 1 & 0 & 0 & 1 \\
\hline \multicolumn{7}{|l|}{ Prática religiosa } \\
\hline Sim & 11 & 23 & 115 & 12 & 7 & 168 \\
\hline Não & 4 & 27 & 83 & 12 & 1 & 127 \\
\hline Ignorado & 1 & 0 & 4 & 0 & 0 & 5 \\
\hline \multicolumn{7}{|l|}{$\begin{array}{l}\text { M ora com mãe/pai e/ou } \\
\text { companheiro }\end{array}$} \\
\hline $\mathrm{Sim}$ & 15 & 38 & 166 & 19 & 4 & 242 \\
\hline Não & 1 & 12 & 34 & 4 & 4 & 55 \\
\hline Ignorado & 0 & 0 & 3 & 1 & 0 & 4 \\
\hline \multicolumn{7}{|l|}{ Escolaridade } \\
\hline 8 anos e mais & 11 & 32 & 160 & 15 & 6 & 224 \\
\hline$\leq 7$ anos & 5 & 18 & 41 & 9 & 2 & 75 \\
\hline Ignorado & 0 & 0 & 2 & 0 & 0 & 2 \\
\hline \multicolumn{7}{|l|}{ Faixa de renda } \\
\hline$>R \$ 1000,00$ & 5 & 14 & 83 & 11 & 3 & 116 \\
\hline$\leq \mathrm{R} \$ 1000,00$ & 9 & 32 & 109 & 9 & 5 & 164 \\
\hline Ignorado & 2 & 4 & 11 & 4 & 0 & 21 \\
\hline \multicolumn{7}{|l|}{ Ocupação } \\
\hline Não estuda nem trabalha & 0 & 1 & 7 & 4 & 1 & 13 \\
\hline Estuda & 7 & 16 & 26 & 6 & 1 & 56 \\
\hline Trabalha & 4 & 21 & 97 & 11 & 4 & 137 \\
\hline Trabalha e estuda & 5 & 12 & 59 & 2 & 1 & 79 \\
\hline Ignorado & 0 & 0 & 14 & 1 & 1 & 16 \\
\hline \multicolumn{7}{|l|}{ Papel da vítima } \\
\hline Passageiro & 0 & 4 & 46 & 17 & 4 & 71 \\
\hline Condutor & 0 & 46 & 155 & 7 & 1 & 209 \\
\hline Pedestre & 16 & 0 & 0 & 0 & 0 & 16 \\
\hline Outro & 0 & 0 & 0 & 0 & 3 & 3 \\
\hline Ignorado & 0 & 0 & 2 & 0 & 0 & 2 \\
\hline
\end{tabular}




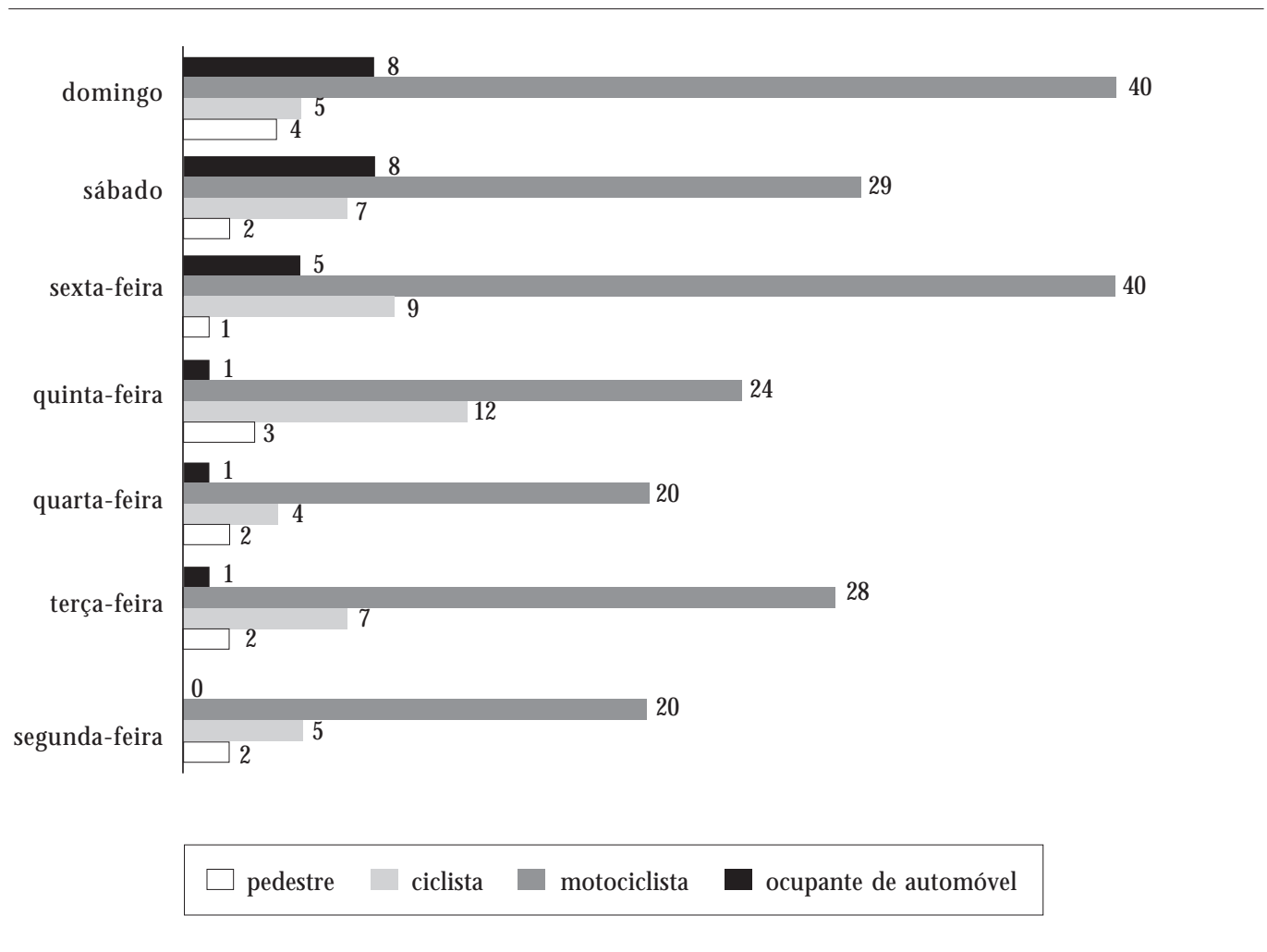

Gráfico 2. Distribuição do número de acidentes de transporte com 290 indivíduos de 15 a 24 anos, residentes no município de Goiânia (GO) e atendidos no HUGO, segundo o dia da semana de ocorrência do acidente. Goiânia (GO), agosto de 2005 a agosto de 2006.

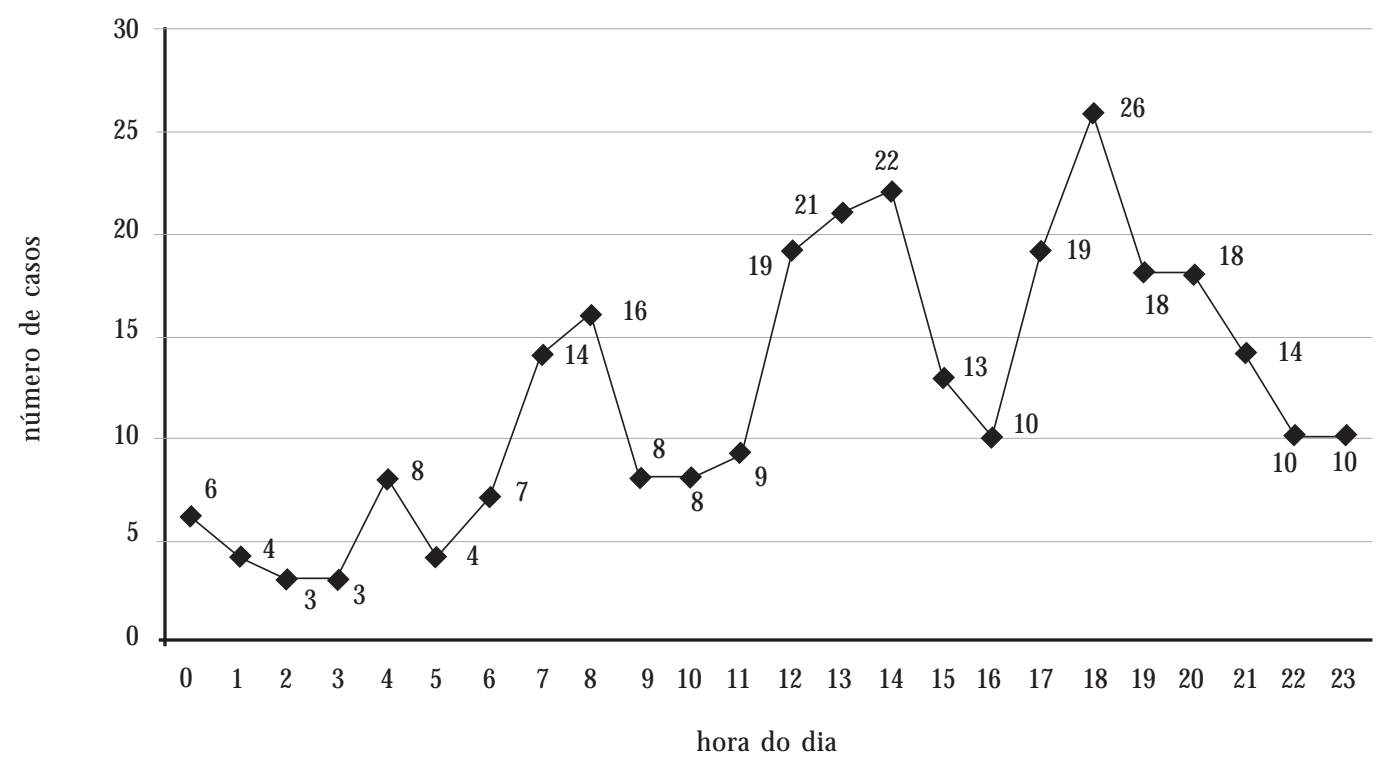

Gráfico 3. Número de casos de acidentes de transporte em 290 indivíduos de 15 a 24 anos, residentes no município de Goiânia (GO) e atendidos no HUGO, segundo o horário de ocorrência. Goiânia (GO), agosto de 2005 a agosto de 2006. 
A Tabela 2 apresenta as circunstâncias em que ocorreram os acidentes de acordo com o meio de transporte usado pelas vítimas atendidas. Os acidentes ocorreram predominantementedurante 0 trajeto para atividades escolares, físicas, esportivas, de lazer eentretenimento edurantetrabalho pago. Ocupantes de automóveis sofreram mais acidentes que motociclistas duranteo trajeto para atividades físicas, esportivas, escolares, de lazer e entretenimento $(p<0,01)$. Por outro lado, motociclistas sofreram mais acidentes durante 0 trabalho pago que ocupantes de automóveis $(p<0,01)$.

A possibilidade de ter havido alguma imprudência ou negligência no acidentefoi relatada por $63,29 \%$ das vítimas, predominantemente composta por motociclistas. Dentre os entrevistados, a maioria dos casos com suspeita ou evidência de uso deálcool e/ou drogas por pelo menosum dos envolvidos no acidente eram motociclistas. Contudo, a proporção de vítimas com suspeita ou evidência de uso de álcool e/ou drogas foi maior entre ocupantes de automóveis que entre motociclistas $(p<0,005)$.

\section{Discussão}

Goiânia foi uma cidade planejada para 50 mil habitantes e, 68 anos após a sua inauguração, possuía uma população de mais de 1.000 .000 de habitantes ${ }^{16}$. 0 trânsito sofre influência das cidades vizinhas que formam a região metropolitana, levando a uma grande demanda nas vias de tráfego que, sem grandes investimentos por parte do setor público, apresentam pontos críticos que favorecem a ocorrência dos acidentes.

Os resultados referentes à predominância do sexo masculino entre vítimas jovens em acidentes de transporte confirmam os resultados de vários estudo ${ }^{17-20}$. A predominância do sexo masculino se deve, provavelmente, à maior exposição dos homens no trânsito, influenciada social e culturalmente para que assumam maiores riscos ao conduzir veículos ${ }^{21}$.

0 alto número de casos deacidentes detransporte nos finais de semana e no início da noite, encontrados neste estudo, são semel hantes aos achados de outros autores ${ }^{18,22-26}$. Estudos realizados em Londrina e Ponta Grossa (PR) aponta-

Tabela 2. Circunstâncias dos acidentes de transporte com vítimas de idade entre 15 e 24 anos, residentes no município de Goiânia (GO) e atendidas no HUGO, de acordo com o meio de transporte. Goiânia (GO), 2006.

\begin{tabular}{|c|c|c|c|c|c|c|}
\hline \multirow[b]{2}{*}{ Circunstâncias do acidente } & \multicolumn{5}{|c|}{ M eio de transporte } & \multirow[b]{2}{*}{$\begin{array}{l}\text { Total } \\
\mathrm{N}=301\end{array}$} \\
\hline & $\begin{array}{l}\text { Pedestre } \\
\mathrm{N}=16\end{array}$ & $\begin{array}{l}\text { Ciclista } \\
\mathrm{N}=50\end{array}$ & $\begin{array}{l}\text { M otociclista } \\
\mathrm{N}=203\end{array}$ & $\begin{array}{c}\text { Ocupante de } \\
\text { automóvel } \\
\mathrm{N}=24\end{array}$ & $\begin{array}{l}\text { Outros } \\
\mathrm{N}=8\end{array}$ & \\
\hline \multicolumn{7}{|l|}{ Atividade } \\
\hline $\begin{array}{l}\text { Trajeto para atividades físicas, } \\
\text { escolares, lazer }\end{array}$ & 5 & 16 & 95 & 19 & 2 & 137 \\
\hline Trabalho pago & 4 & 16 & 69 & 2 & 4 & 95 \\
\hline Trabalho não pago & 5 & 4 & 17 & 0 & 0 & 26 \\
\hline Atividades de lazer & 2 & 10 & 9 & 0 & 1 & 22 \\
\hline Outras especificadas & 0 & 3 & 4 & 3 & 0 & 10 \\
\hline Ignorado & 0 & 1 & 9 & 0 & 1 & 11 \\
\hline \multicolumn{7}{|l|}{$\begin{array}{l}\text { Uso de álcool e/ou drogas } \\
\text { por algum dos envolvidos }\end{array}$} \\
\hline Sim & 4 & 5 & 24 & 9 & 1 & 43 \\
\hline Não & 11 & 44 & 167 & 13 & 6 & 241 \\
\hline Ignorado & 1 & 1 & 12 & 2 & 1 & 17 \\
\hline \multicolumn{7}{|l|}{ Imprudência/negligência } \\
\hline Sim & 11 & 21 & 119 & 15 & 3 & 169 \\
\hline Não & 3 & 23 & 60 & 8 & 4 & 98 \\
\hline Ignorado & 2 & 6 & 24 & 1 & 1 & 34 \\
\hline
\end{tabular}


ram a fadiga ao fim do dia e a elevação do fluxo de veículos como fatores que poderiam aumentar o número de acidentes e de vítimas ${ }^{24,27}$. O utros fatores também foram associados ao maior número de acidentes e de vítimas no período noturno ${ }^{23,25}$ foram a variação da visibilidade limitada pelo alcance dos faróis, uso de roupas escuras pelos pedestres, veículos não sinalizados e pequeno contraste com o ambiente, excesso de velocidade, desrespeito à sinalização e uso de álcool ou drogas.

M otoristas jovens são inexperientes no enfrentamento de algumas situações que ocorrem no trânsito, na condução de veículo no período noturno e quando transportam jovens passageiros ${ }^{28,29}$. A concentração de acidentes nosfinais de semana e no início da noite deve orientar o planejamento dos serviços responsáveis pela assistência às vítimas, reforçando suas equipes de trabal ho e o suprimento de materiais necessários para $o$ atendimento.

Devido à associação entreo uso de bebida alcoólica e a ocorrência de acidentes $5^{21,22,30}$, especialmente de jovens e adultos joven ${ }^{31}$, programas de prevenção deacidentes costumam focalizar os riscos de dirigir alcoolizado. Em São Paulo (SP), $24,2 \%$ das vítimas de acidentes de transporte que procuraram serviço de trauma apresentavam alcoolemia positiva ${ }^{32}$, mostrando a necessidade de programas dessa natureza. Em Goiânia, existem poucas opções de lazer para jovens, mas alto número de bares. M edidas educativas poderiam ser implementadas, buscando parcerias com estes estabelecimentos em relação ao uso conscientedo álcool eà direção de veículos.

A proporção de vítimas com primeiro grau incompleto obtida foi semelhante ao do estudo realizado em Belo H orizonte ${ }^{33}$. Contudo, parcela importantedos jovens de Goiânia ainda frequentava a escola (45,91\%). A escola pode oferecer boa oportunidade de intervenção, tendo em vista a importância da educação na prevenção dos acidentes de transporte. A busca do envolvimento das escolas no desenvolvimento de políticas públicas parece ser um caminho natural para prevenção e redução dos acidentes de trânsito a médio e longo prazo, por meio do acompanhamento dos pais e da formação de pedestres e motoristas mais conscientes ${ }^{34,35}$. 0 próprio Código deTrânsito Brasileiro preconiza quea União, estados, municípios e o Distrito Federal devem interagir para promover a educação para o trânsito, da pré-escola ao terceiro grau ${ }^{36}$.

A pesar da maioria das vítimas estudadas serem trabalhadores, eles se acidentaram mais aos finais de semana, o que podejustificar a alta ocorrência durante o trajeto para as atividades físicas, esportivas, escolares, lazer/entretenimento. Também foi elevada a proporção de acidentes ocorridos durante a realização de trabal ho pago (principalmente os motociclistas). Uma revisão sobre acidentes ocupacionais apontou que os acidentes de trânsito são a causa mais frequente de acidentes de trabal ho fatais ${ }^{37}$. A precocidade da entrada no mercado de trabal ho pode contribuir para a melhoria da renda familiar, mas também pode aumentar a exposição aos acidentes de transporte, particularmente para motociclistas jovens.

0 meio de transporte mais prevalente entre as vítimas de acidentes de transporte foi a motocicleta $(67,54 \%)$, resultado superior ao encontrado em Maringá (PR), 46,19\% ${ }^{38}$. Dados do M inistério das Cidades mostram que Goiânia contava com 114.300 motos em dezembro de $2006^{9}$, uma moto para cada nove habitantes. Dentre os fatores que estimulam o aumento da frota de motocicletas estão o baixo custo para aquisição e manutenção, facilidades para deslocamento e estacionamento e uso para entrega de mercadorias etransporte de passageiros ${ }^{21}$. A busca de aumento da produtividade adotando medidas inseguras, tais como manobras arriscadas e alta velocidade, podem explicar a alta ocorrência deacidentes ocupacionais com motocicletas ${ }^{21}$.

A prevalência encontrada de acidentes com bicicleta foi semelhante à de Londrina (PR) $(20,9 \%)^{21}$. Em Goiânia, não existem ciclovias, que poderiam oferecer mais segurança a esses usuários. 0 baixo número de vítimas de atropelamento ( 28 acidentes com colisão envolvendo ciclistas, dados não mostrados) pode ser explicado pela faixa etária do estudo; no Rio de Janeiro (RJ), émais frequente entremenores de dez anos e maiores de 65 anos $^{39}$.

0 baixo uso de equipamentos de segurança pelas vítimas estudadas indica que medidas educativas e de fiscalização precisam ser intensificadas para garantir o cumprimento da legislação em vigor ${ }^{36}$ e para a redução da morbimortalidade. 0 uso de capacete por ciclistas é capaz de reduzir cerca de $60 \%$ dos casos de traumatismo craniano $0^{40}$ e 0 uso de capacete de cor clara por motociclistas reduz em aproximadamente $20 \%$ o risco de lesões e mortes ${ }^{41-43}$.

A maioria dos motociclistas julgou quehouve imprudência ou negligência no acidente, sugerindo queuma parcela importante das vítimas considera queo acidentepoderia ser evitado. Essepoderia ser um fator facilitador na implementação de políticas públicas (tais como educação continua- 
da, liberação gradual da licença para dirigir, com acompanhamento dos pais e/ou com permissão apenas para o horário diurno ${ }^{28}$, melhora da infraestrutura viária, aplicação da lei de trânsito ${ }^{44}$ ) que possibilitaria uma mudança de atitude na prevenção de acidentes por parte da população (como aplicação das recomendações de direção defensiva, uso de equipamentos de segurança ${ }^{41}$ ).

A alta prevalência de acidentes com motociclistas sugere que Goiânia atravessa um período de transição econômica próprio de países em desenvolvimento, com aumento de vítimas vulneráveis oriundas da crescente classe média que compra veículos motorizados particulares e de menor custo, à semelhança do padrão descrito por outros autores ${ }^{44,45}$.

\section{Conclusões}

0 presente estudo pode identificar o perfil das vítimas eas circunstâncias dosacidentes detransporte entre jovens de Goiânia. 0 reconhecimento dessas características pode ser útil para o planejamento de estratégias de prevenção dos acidentes de transporte e para subsidiar a organização do serviço deemergência. 0 elevado número de motociclistas acidentados, homens jovens, requer interven ções urgentes. Parcerias entregoverno, escolas, associações de bares, lanchonetes e de condutores podem promover ações educativas e boas práticas no trânsito.

A análise dos resultados possibilitou, ainda, suscitar hi póteses sobre a eficácia do Código Brasileiro deTrânsito. M ostrou queénecessário tanto 0 aprimoramento do processo educativo de jovens quanto a fiscalização relativa à habilitação dos condutores e ao uso do álcool, capacete e cinto de segurança.

Este estudo analisou casos incidentes e usou dados primários obtidos em serviço de emergência, o que tende a minimizar eventual viés de memória e de seleção de pacientes com sequelas de acidentes ${ }^{46}$. Este parece ser o primeiro estudo na região que procurou mensurar a morbidade por acidentes de transporte em jovens. 0 sistema de vigilância implementado no serviço de emergência durante o período do estudo contribuiu com melhor qualidade dos dados e maximizou a eficiência no recrutamento.
Uma das limitações do estudo é de inclusão de casos que tendem a ser mais graves por se tratar de um grande hospital de referência. Outra limitação é que parte dos dados obtidos foi relatada por vítimas ou familiares e algumas das variáveis (ou seja, uso deálcool ou drogas, renda familiar) podem apresentar viés. Jovense/ou seus familiares com possível culpano acidente podem ter receio de que suas informações possam ser repassadas a autoridades legai ${ }^{47}$. O utros fatores deexposição não puderam ser avaliados em nosso estudo por serem de difícil obtenção em Goiânia, como consumo de álcool/droga nas horas que antecederam o trauma e, nos casos de colisão, dados sobre a outra parte envolvida.

A partir destes resultados, é possível afirmar que os acidentes com motociclistas constituem um problema de saúde pública para a população estudada. Ações de combate a esses acidentes devem priorizar horários de entrada e saída de escolas e trabalho, assim como os finais de semana. A carência de fiscalização pode ter contribuído para a existência demenores deidadedirigindo veículos a motor e para a alta frequência de acidentes de trânsito.

Experiências bem-sucedidas de outras regiões na redução de acidentes de transporte devem ser consideradas no delineamento de intervenções simultâneas governamentais e de diferentes setores da sociedade, bem como na definição de investimentos públicos.

\section{Colaboradores}

CR Caixeta, VV Brasil e RM Faria participaram de todas as etapas da pesquisa. LM AC Oliveira participou da digitação, análise dos dados e redação final. 


\section{Referências}

1. Hyder AA, Peden M. Inequality and road-traffic injuries: call for action. Lancet 2003; 362(9401):20342035.

2. Peden M, Scurfield R, Sleet D. World report on road traffic injury prevention. Geneva: World Health Organization; 2004 [acessado 2006 jun 21]. Disponível em: http://www. paho.org/English/D D/PU B/Summary _World_report_Road_safety.pdf

3. $\bar{M}$ athers $C D$, Loncar $\bar{D}$. Projections of global mortality and burden of disease from 2002 to 2030. PLOS M ed 2006; 3(11):e442.

4. Krug, EG. Injury surveillance is key to preventing injuries. Lancet 2004; 364(9445):1563-1566.

5. Costa JSD, Victora CG. O que é “um problema de saúde pública"? Rev. bras. epidemiol. 2006; 9(1):144146.

6. Pan American Health Organization. Deaths from motor vehicle traffic accidents in selected countries of the Americas, 1985-2001. Epidemiol Bull [periódico na Internet] 2004 [acessado ano mês dia];25(1):[ cerca de 4 p.]. Disponível em: http:// www.paho.org/english/dd/ais/EB_v25n1.pdf

7. Waiselfisz JJ. Mapa da violência 2006 - os jovens do Brasil. Brasília: Organização dos Estados IberoAmericanos para a educação, a ciência e a cultura; 2006. [acessado 2007 fev 26]. Disponível em: http:/ /www.oei.org.br/mapaviolencia.pdf

8. Souza ER, M inayo MCS, M alaquias JV. Violência no trânsito In: Ministério da Saúde. Impacto da violência na saúde dos brasileiros. Brasília: M inistério da Saúde; 2005. p. 280-301.

9. Brasil. Departamento Nacional de Trânsito. [site da Internet] [acessado 2006 mar 01]. Disponível em: http://www.denatran.gov.br

10. Brasil. M inistério da Saúde. Número de óbitos por acidentes de transporte. Brasília: Ministério da Saúde; 2007.

11. Silva MGC. Anos potenciais de vida perdidos por causas evitáveis, segundo sexo, em Fortaleza, em 1996-1998. Epidemiol Serv Saúde 2003;12(2):99-110.

12. Brasil. M inistério da Saúde. Portaria M S/GM 737 de 16 de maio de 2001. Institui a política nacional de redução da morbi-mortalidade por acidentes e violências. Diário Oficial da União 2001; 18 mai.

13. Ameratunga S, Hijar M, Norton R. Road-traffic injuries: confronting disparities to address a globalhealth problem. Lancet 2006; 367(9521):1533-1540.

14. Brasil. M inistério da Saúde. População residente Brasil. Brasília: Ministério da Saúde; 2007.

15. Epilnfo ${ }^{\top M}$, a data base and statistics program for public health professionals [programa de computador]. Atlanta: Centers for Disease Control and Prevention; 2002.

16. Instituto Brasileiro de Geografia e Estatística. Censo Demográfico 2000. Rio de Janeiro: IBGE; 2000.

17. Koizumi MS. Acidentes de motocicleta no município de São Paulo, SP (Brasil): 1. Caracterização do acidente e da vítima. Rev. Saude Publica 1985; 19(5):475-489.

18. Scalassara MB, Souza RKT, Soares DFPP. Características da mortalidade por acidentes de trânsito em localidade da região sul do Brasil. Rev. Saude Publica 1998; 32(2):125-132.
19. Lima FM, M uniz RB, Lopes CM. Mortality for accidents of traffic in Rio Branco - Acre - Brazil, 2001 to 2003. OBJN [periódico na Internet] 2004 [acessado ano mês dia]; 3(3). Disponível em: http:// www.uff.br/nepae/objn303limaetal.htm

20. Hyder AA, Amach OH, Garg N, Labinjo MT. Estimating the burden of road traffic injuries among children and adolescents in urban South Asia. Health Policy 2006; 77(2):129-139.

21. Andrade SM, M ello Jorge M H P. Características das vítimas por acidentes de transporte terrestre em município da Região Sul do Brasil. Rev. Saude Publica 2000;34(2):149-156.

22. Barros AJD, Amaral RL, Oliveira MSB, Lima SC, Gonçalves EV. Acidentes de trânsito com vítimas: sub-registro, caracterização e letalidade. Cad Saude Publica 2003;19(4):979-986.

23. Leibowitz HW, Owens DA, Tyrrell RA. The assured clear distance ahead rule: implications for nighttime traffic safety and the law. Accid Anal Prev 1998; 30(1):93-99.

24. Andrade SM, M ello Jorge MHP. Acidentes de transporte terrestre em município da Região Sul do Brasil. Rev. Saude Publica 2001; 35(3):318-320.

25. Bastos, YGL, Andrade, SM, Soares, DA. Características dos acidentes de trânsito e das vítimas atendidas em serviço pré-hospitalar em cidade do Sul do Brasil, 1997/2000. Cad Saude Publica 2005; 21(3):815-822.

26. Soares DFPP, Barros M BA. Fatores associados ao risco de internação por acidentes trânsito no município de Maringá-PR. Rev. bras. epidemiol. 2006; 9(2):193-205.

27. Stocco C, Leite ML, Virgens Filho JS, Labiak VB. Caracterização epidemiológica dos acidentes de trânsito ocorridos dentro do perímetro urbano de Ponta Grossa, Paraná, 2002 -2004. Espac Saúde 2006; $7(2): 8-16$

28. Williams AF, Ferguson SA. Rationale for graduated licensing and the risks it should address. Inj Prev 2002; 8(Suppl 2):ii9-ii16.

9. Chen IG, Durbin DR, Elliott MR, Senserrick T, Winston FK. Child passenger injury risk in motor vehicle crashes: a comparison of nighttime and daytime driving by teenage and adult drivers. J Safety Res 2006; 37(3):299-306.

30. Mello Jorge MHP, Gawryszewski VP, Latorre MRDO. I - Análise dos dados de mortalidade. Rev. Saude Publica 1997; 31(4):5-25.

31. Keall MD, Frith WJ, Patterson TL. The contribution of alcohol to night time crash risk and other risks of night driving. Accid Anal Prev 2005; 37(5):816-824.

32. Gazal-Carvalho C, Cotrim BC, Silva OA, Sauaia N. Prevalência de alcoolemia em vítimas de causas externas admitidas em centro urbano de atenção ao trauma. Rev. Saude Publica 2002; 36(1):47-54.

33. Belo H orizonte. Saúde em trânsito: pesquisa de acompanhamento de vítimas de acidentes de trânsito em Belo Horizonte. Belo Horizonte: Prefeitura de Belo H orizonte/Secretaria de Saúde/BHTRAN S; 2005.

34. Faria EO, Braga M GC. Propostas para minimizar os riscos de acidentes de trânsito envolvendo crianças e adolescentes. Cien Saude Colet 1999; 4(1):95-107. 
35. Fatimah M, Osman A, Masyarakat JK, Perubatan F. The risk of road traffic accidents among primary school children in Kuala Terengganu. Med J Malaysia 1997; 52(4):402-408.

36. Brasil. Lei 9.503 de 23 setembro de 1997. Dispõe sobre o Código de Trânsito Brasileiro. Diário Oficial da União 1997; 23 set.

37. M endes R. O impacto dos efeitos da ocupação sobre a saúde de trabalhadores: II - M ortalidade. Rev. Saude Publica 1988; 22(5):441-457.

38. Oliveira NLB, Sousa RM C. M otociclistas frente às demais vítimas de acidentes de trânsito no município de Maringá. Acta Scientiarum Health Sciences 2004; 26(2):303-310.

39. Klein CH. Mortes no trânsito do Rio de Janeiro, Brasil. Cad Saude Publica 1994; 10(suppl.1):S168-S76.

40. Waksman RD, Pirito RM. O pediatra e a segurança no trânsito. J Pediatr (Rio J.) 2005; 81(5):S181-S88.

41. Liu B, Ivers R, Norton R, Blows S, Lo SK. Helmets for preventing injury in motorcycle riders. Cochrane Database Syst Rev 2004; (2):CD 004333.

42. Wells S, Mullin B, Norton R, Langley J, Connor J, Lay-Yee R, Jackson R. M otorcycle rider conspicuity and crash related injury: case-control study. BM J 2004; 328(7444):857.

43. Shibata A, Fukuda K. Risk factors of fatality in motor vehicle traffic accidents. Accid Anal Prev 1994; 26(3):391-397.

44. Nantulya VM, Reich M R. The neglected epidemic: road traffic injuries in developing countries. BM J 2002; 324(7346):1139-1141.

45. Paulozzi LJ, Ryan GW, Espitia-Hardeman VE, Xi Y. Economic development's effect on road transportrelated mortality among different types of road users: a cross-sectional international study. Accid Anal Prev 2007; 39(3):606-617.

46. Kendrick D, Lyons R, Christie N, Towner E, Benger J, Groom L, Coffey F, Miller P, Murphy R; UK Burden of Injury Study. Recruiting participants for injury studies in emergency departments. Inj Prev 2007; 13(2):75-77.

47. Cummings P, Koepsell TD, Mueller BA. Methodological challenges in injury epidemiology and injury prevention research. Annu Rev Public Health 1995; 16:381-400.

Artigo apresentado em 02/01/2008

Aprovado em 15/03/2008

Versão final apresentada em 24/03/2008 